\title{
Comparative prevalence of asthma in different groups of athletes: A survey
}

\author{
Jean-Bruno Langdeau PhD, Hélène Turcotte MSc, Guy Thibault PhD, Louis-Philippe Boulet MD FRCPC
}

\begin{abstract}
J-B Langdeau, H Turcotte, G Thibault, L-P Boulet. Comparative prevalence of asthma in different groups of athletes: A survey. Can Respir J 2004;11(6):402-406.
\end{abstract}

BACKGROUND: The type of air predominantly inhaled during training seems to play an important role in the development of airway hyperresponsiveness in athletes; however, this factor has not been evaluated for asthma.

OBJECTIVE AND PATIENTS: To compare the prevalence of self-reported and/or physician-diagnosed asthma among four groups of athletes categorized according to the type of air predominantly inhaled during training: cold air $(n=176)$, dry air $(n=384)$, humid air $(n=95)$, and mixed dry and humid air $(n=43)$.

METHOD: Self-administrated questionnaires were used.

RESULTS: One hundred seven (15.3\%) of the 698 athletes reported having asthma; of these 107 athletes, 92 had physician-diagnosed asthma. No significant differences were found for the prevalence of asthma: $15.9 \%$ (cold air), 15.4\% (dry air), 12.6\% (humid air) and $18.6 \%$ (mixed dry and humid air), respectively ( $\mathrm{P}>0.05)$. Furthermore, no significant differences were observed among the groups for the prevalence of confirmed atopy, cold/flu or respiratory infections (all $\mathrm{P}>0.05$ ), except for the prevalence of hay fever, which was significantly lower among athletes of the dry air group $(\mathrm{P}=0.04)$. Athletes having a first-degree relative with asthma did not have a higher prevalence of asthma than those who did not $(\mathrm{P}>0.05)$.

CONCLUSION: The prevalence of asthma was not significantly different among the four groups of athletes and it was not associated with a family history of asthma.

Key Words: Asthma; Athletes; Prevalence; Survey

\section{La prévalence comparative de l'asthme chez divers groupes d'athlètes : Une enquête}

HISTORIQUE : Le type d'air principalement inhalé pendant l'entraînement semble occuper une fonction importante dans l'apparition d'une hypersensibilité des voies aériennes chez les athlètes. Toutefois, ce facteur n'a pas été évalué pour l'asthme.

OBJECTIF ET PATIENTS : Comparer la prévalence d'asthme déclaré par le patient ou diagnostiqué par un médecin au sein de quatre groupes d'athlètes classés selon le type d'air principalement inhalé pendant l'entraînement : air froid $(n=176)$, air sec $(n=384)$, air humide $(n=95)$ et mélange d'air sec et d'air humide $(\mathrm{n}=43)$.

MÉTHODOLOGIE : Questionnaires à remplir soi-même

RÉSULTATS : Cent sept (15,3\%) des 698 athlètes ont déclaré être asthmatiques. De ce nombre, 92 souffraient d'asthme diagnostiqué par un médecin. Aucune différence significative n'a été observée pour ce qui est de la prévalence de l'asthme : 15,9 \% (air froid), 15,4\% (air sec), 12,6\% (air humide) et 18,6 \% (mélange d'air sec et d'air humide), respectivement $(\mathrm{P}>0,05)$. De plus, aucune différence significative n'a été observée parmi les groupes pour ce qui est de la prévalence d'atopie confirmée, de rhume ou de grippe ou d'infections respiratoires (tous $\mathrm{P}>0,05$ ), sauf en ce qui a trait à la prévalence de rhume des foins, qui était beaucoup plus faible chez les athlètes du groupe respirant de l'air sec $(P=0,04)$. Les athlètes dont un parent du premier degré était asthmatique ne présentaient pas de prévalence d'asthme plus élevée que les autres $(P>0,05)$.

CONCLUSION : La prévalence d'asthme n'était pas considérablement différente entre les quatre groupes d'athlètes et ne s'associait pas à des antécédents familiaux d'asthme.

\begin{abstract}
A sthma and airway hyperresponsiveness (AHR) are more prevalent in athletes than in the general population $(1,2)$. Studies (3-5) using methacholine or histamine challenges to evaluate AHR identified a high prevalence of AHR in various sports disciplines; however, studies (6-9) using surveys to evaluate asthma among the athletic population reported a significantly lower prevalence of physician-diagnosed asthma than that reported for AHR. This phenomenon had already been observed among the general population, but in athletes, the reason for the discrepancy between the prevalence of AHR and the diagnosis of asthma remains to be determined. It might be attributed to poor perception of respiratory symptoms or to an acquired tolerance to nociceptive symptoms. Another explanation might be that a high percentage of athletes have developed asymptomatic AHR, with no clinical manifestations.

In a previous study (4), we looked at the prevalence of AHR in four different groups of athletes categorized according to the type of air predominantly inhaled when training: cold air

(CA), dry air (DA), humid air (HA) and a mixture of dry and humid air (MA). The prevalence of AHR was significantly higher $(49 \%)$ in all athletes than in sedentary subjects $(28 \%)$, but surprisingly, very few athletes reported having a diagnosis of asthma $(16 \%)$. When the prevalence of AHR among the groups of athletes was compared, we found significant differences. Athletes of the CA group (cross-country skiers, biathletes and speed skaters) and the HA group (swimmers) had significantly higher prevalences of AHR than the two other groups. The prevalence of AHR was not significantly different between athletes of the DA and MA groups and the sedentary group. The main objective of the present study was to evaluate and compare the prevalence of asthma among four groups of athletes categorized according to the type of air predominantly inhaled during training. In addition, the possible influences of a family history of asthma and of living environment on the development of asthma in these athletes were examined.
\end{abstract}

Centre de Recherche de l'Hôpital Laval, Institut Universitaire de Cardiologie et de Pneumologie, Université Laval, Quebec City, Quebec

Correspondence: Dr Louis-Philippe Boulet, Hôpital Laval, 2725 Chemin Sainte-Foy, Quebec City, Quebec G1V 4G5.

Telephone 418-656-4747, fax 418-656-4762, e-mail lpboulet@med.ulaval.ca 


\section{TABLE 1}

\section{Questionnaire* $^{*}$}

1. Have you ever suffered from asthma?

2. Have you ever been diagnosed as having asthma by a physician? If yes, was your asthma defined as very light, light, moderate or severe?

3. Have you ever visited an emergency department for asthma?

4. Have you ever been hospitalized for asthma?

5. Which medications are you taking or were you taking for your asthma?

6. Have you ever had any of these symptoms with exercise: breathlessness, wheezing, cough, throat spells or chest tightness?

7. Have you ever been tested for allergies? If yes, to which of the following were you allergic: mites, dust mites, grass, ragweed, trees, animals or any others (name them)?

8. Do you ever remember having suffered from: hay fever, eczema, and/or urticaria?

9. How many times did you have cold or flu in the last 12 months?

10. Do you frequently have bronchitis?

11. Do you ever remember suffering from a respiratory infection (other than cold or flu)?

12. Is there one member of your family (father, mother, brother or sister) that has ever had one of the following conditions: asthma, allergies and/or emphysema?

13. Which of the following are present where you live: cat, dog and/or car pet in your bedroom?

14. Are you a current smoker? If yes, do you smoke less than 5 cigarettes/day, or 5 or more cigarettes/day?

15. Are you an exsmoker? If yes, were you smoking less than 5 cigarettes/day, or 5 or more cigarettes/day?

${ }^{*}$ Translated from French

\section{METHODS}

\section{Study design and subjects}

From the 33 sports disciplines selected for the study, a list of 1469 athletes from the province of Quebec was produced by the sports and physical activity branch of the government of Quebec. A letter explaining the purpose of the survey was sent to each athlete, offering the opportunity to take part in the survey by filling out an enclosed questionnaire (in French). All athletes received a second letter as a reminder four weeks after the initial mailing. The study protocol was approved by the Laval Hospital (Quebec City, Quebec) institutional ethics committee. Seven hundred questionnaires were returned; two questionnaires that were not properly filled out were eliminated. An analysis was performed on the remaining 698 anonymous questionnaires.

\section{Questionnaire}

Questions included personal history of asthma (self-reported and physician-diagnosed); severity of asthma; health care system use and medication for asthma; previous allergy testing; past or present history of hay fever; respiratory infections; episodes of cold in the past 12 months; and a family history of asthma, allergies and chronic obstructive pulmonary disease (COPD). Environmental conditions, such as exposure to domestic animals, bedroom carpeting and smoking history, were also recorded. The questionnaire structure is illustrated in Table 1. Questions used in the present survey
TABLE 2

Subject characteristics

\begin{tabular}{lc}
\hline Sex $(M: F)$ & $314: 384$ \\
Mean age $( \pm \mathrm{SD})($ years $)$ & $19.0 \pm 4.0$ \\
Weight $($ mean $\pm \mathrm{SD})(\mathrm{kg})$ & $68.8 \pm 15.6$ \\
Height $($ mean $\pm \mathrm{SD})(\mathrm{cm})$ & $173.1 \pm 12.1$ \\
Body mass index $($ mean $\pm \mathrm{SD})\left(\mathrm{kg} / \mathrm{m}^{2}\right)$ & $23.0 \pm 7.5$ \\
Mean years in their sports discipline $( \pm \mathrm{SD})$ & $8.8 \pm 4.0$ \\
Mean h/week training in their respective sports disciplines $( \pm \mathrm{SD})$ & $14.7 \pm 7.6$ \\
Mean h/week allowed to training in general $( \pm \mathrm{SD})$ & $22.9 \pm 10.9$ \\
\hline
\end{tabular}

F Female; M Male

included some from the validated questionnaire of the European Community Respiratory Health Survey (10) to which specific questions on exercise-related symptoms were added.

In the analysis, athletes were considered to have a positive history of asthma if they self-reported having asthma and/or had had physician-diagnosed asthma at any time. To evaluate the impact of different training environments, according to the type of air inhaled during training, on the respiratory health and allergic conditions in athletes, the four groups of athletes, as described in the introduction, were compared.

\section{Statistical analysis}

The results are expressed as mean $\pm \mathrm{SD}$ and per cent for categorical variables. The analyses of continuous variables were performed using a one-way ANOVA. Subgroups were defined as CA, DA, HA and MA. Comparisons among groups were performed using Scheffe's multiple comparison technique. The normality assumption was verified with the Shapiro-Wilk test, and Bartlett's statistic was used to verify the homogeneity of variances. Categorical variables were analysed using Fisher's exact test. Results were considered significant if $\mathrm{P} \leq 0.05$. Data were analysed using the statistical package SAS (SAS Institute Inc, USA).

\section{Subject characteristics}

\section{RESULTS}

Among the participating athletes, $45 \%$ were males and 55\% were females (Table 2). The majority were white $(95 \%)$ and most were young $(19.0 \pm 4.0$ years). The number of years and time spent training weekly are summarized in Table 2 . The distribution of athletes for the 33 sports disciplines is illustrated in Table 3 . The number of sports disciplines by category of athlete were eight in the CA group, 19 in the DA group, three in the HA group and three in the MA group (Table 3 ).

\section{Prevalence of asthma}

According to the criteria (athletes self-reporting asthma and/or having had physician-diagnosed asthma), 107 of 698 subjects $(15.3 \%)$ had a past or present history of asthma; among these subjects, 92 stated that a physician had made the diagnosis of asthma. Table 3 illustrates the prevalence of asthma within each sports discipline.

Prevalence of asthma by group analysis

The prevalence of asthma varied from $12.6 \%$ to $18.6 \%$ among the four groups but no significant differences were observed (Table 4). 
TABLE 3

Prevalence of asthma* in various sports disciplines

\begin{tabular}{|c|c|c|}
\hline Sports disciplines & Number of subjects & $\begin{array}{c}\text { Prevalence of asthma } \\
n(\%)\end{array}$ \\
\hline Cold air & 176 & \\
\hline Alpine skiing & 12 & $6(50.0)$ \\
\hline Biathlon & 6 & $1(16.7)$ \\
\hline Cross-country skiing & 20 & $3(15.0)$ \\
\hline Curling & 11 & $1(9.1)$ \\
\hline Figure skating & 22 & $7(31.8)$ \\
\hline Hockey & 74 & $8(10.8)$ \\
\hline Snowboard & 9 & $0(0)$ \\
\hline Speed skating & 22 & $2(9.1)$ \\
\hline Dry air & 384 & \\
\hline Badminton & 12 & $2(16.7)$ \\
\hline Basketball & 30 & $5(16.7)$ \\
\hline Boxing & 13 & $2(15.4)$ \\
\hline Cycling & 31 & $10(32.3)$ \\
\hline Football & 22 & $2(9.1)$ \\
\hline Gymnastics & 32 & $1(3.0)$ \\
\hline Handball & 26 & $2(7.7)$ \\
\hline Judo & 24 & $3(12.5)$ \\
\hline Racquetball & 13 & $2(15.4)$ \\
\hline Ringette & 18 & $2(11.1)$ \\
\hline Rugby & 15 & $2(13.3)$ \\
\hline Running & 10 & $1(10.0)$ \\
\hline Squash & 2 & $0(0)$ \\
\hline Tennis & 13 & $5(38.5)$ \\
\hline Track and field & 26 & $4(15.3)$ \\
\hline Volleyball & 50 & $7(14.0)$ \\
\hline Weight lifting & 15 & $3(20.0)$ \\
\hline Wrestling & 4 & $0(0)$ \\
\hline Humid air & 95 & \\
\hline Swimming & 44 & $8(18.2)$ \\
\hline Synchronized swimming & 18 & $3(16.7)$ \\
\hline Water polo & 33 & $1(3.0)$ \\
\hline Mixed air & 43 & \\
\hline Canoe and kayak & 28 & $5(17.9)$ \\
\hline Rowing & 13 & $2(15.4)$ \\
\hline Triathlon & 2 & $1(50.0)$ \\
\hline
\end{tabular}

*Self-reported and/or physician-diagnosed asthma

Severity of asthma and health care use

Of the 92 athletes with physician-diagnosed asthma, 17 described the severity of their asthma as very mild, 37 as mild, 22 as moderate and 14 as severe. Two athletes did not rate the severity of their asthma. Of the 92 athletes, 42 (45.7\%) reported having visited the emergency department at least once for asthma and $13(14.1 \%)$ reported having been hospitalized for asthma.

\section{Asthma medication}

Of the 92 athletes with physician-diagnosed asthma, $68(73.9 \%)$ reported current or past use of asthma medication. Among these athletes, 38 used inhaled short-acting beta 2 agonists alone, five used inhaled corticosteroids alone, 23 used inhaled corticosteroids in combination with short-acting beta ${ }_{2}$ agonists, one used long-acting beta ${ }_{2}$-agonists alone and one used inhaled corticosteroids in combination with a leukotrienereceptor antagonist. There was no report of asthma medication use among nonasthmatic athletes.
TABLE 4

Prevalence of various conditions among the four groups of athletes

\begin{tabular}{|c|c|c|c|c|c|}
\hline Conditions & $\begin{array}{c}\mathrm{CA} \\
(\mathrm{n}=176)\end{array}$ & $\begin{array}{c}\text { DA } \\
(n=384)\end{array}$ & $\begin{array}{c}\text { HA } \\
(n=95)\end{array}$ & $\begin{array}{c}\text { MA } \\
(n=43)\end{array}$ & $\mathbf{P}$ \\
\hline Asthma* & $28(15.9)$ & $59(15.4)$ & $12(12.6)$ & $8(18.6)$ & NS \\
\hline Allergies* & $31(17.6)$ & $82(21.4)$ & $23(24.2)$ & $7(16.3)$ & NS \\
\hline Hay fever* & $47(26.7)$ & $65(16.9)^{\dagger}$ & $23(24.2)$ & $10(23.3)$ & 0.04 \\
\hline Cold/influenza* & $142(80.7)$ & $310(80.7)$ & $65(68.4)$ & $35(81.4)$ & NS \\
\hline $\begin{array}{l}\text { Respiratory } \\
\text { infections* }\end{array}$ & $25(14.2)$ & $43(11.2)$ & $14(14.7)$ & $8(18.6)$ & NS \\
\hline
\end{tabular}

Group analysis according to the type of air predominantly inhaled during training. ${ }^{*}$ Number of subjects (\%); 'Significantly different from the other groups; $\neq$ In the last 12 months. CA Cold air, DA Dry air; HA Humid air; MA Mixed air; NS Not significant $(P<0.05)$

Exercise-induced symptoms

Respiratory symptoms reported with exercise were (percentage of subjects): breathlessness (48.6\%), wheezing (15.6\%), cough (15.2\%), phlegm production (22.6\%) and chest tightness (7.4\%).

\section{Allergic conditions}

Of 159 athletes who reported having been tested for allergies, $143(89.9 \%)$ reported having had at least one positive response (Table 5). Atopic athletes reported positive tests for the following specific allergens: house dust (56.6\%), dust mites (35.0\%), grasses $(19.6 \%)$, ragweed $(33.6 \%)$, trees $(24.5 \%)$, animal dander $(51.0 \%)$ and other $(52.4 \%)$. The presence of allergy (defined as at least one positive test) was highly correlated with asthma $(\mathrm{P}<0.0001)$. Atopy was significantly higher in asthmatic athletes (56 of 107, 52.3\%) than in nonasthmatic athletes (87 of $591,14.7 \%)$. Hay fever, which was reported by 145 athletes, was also highly correlated with asthma $(\mathrm{P}<0.0001)$. By group analysis (CA, DA, HA and MA), there were no significant differences in the prevalence of atopy among the four groups; however, athletes from the DA group had a lower prevalence of hay fever than observed in the other three groups $(\mathrm{P}=0.04$, Table 4).

\section{Respiratory health}

The majority of athletes (79.1\%) reported at least one episode of cold/influenza in the last 12 months, but this parameter was not correlated with asthma. A smaller percentage of athletes reported having suffered from respiratory infection (12.9\%), this parameter was highly correlated with asthma $(\mathrm{P}<0.0001)$. Cold/influenza and respiratory infection prevalences were not significantly different among the four groups of athletes (Table 4).

Family history

A family history of asthma and allergy was not significantly correlated with asthma in athletes, although a family history of COPD was significantly correlated to asthma in athletes $(\mathrm{P}=0.002)$ (Table 5).

Living environment and smoking

The prevalence of asthma in athletes exposed to cats, dogs or had bedroom carpeting in their living environment was not significantly different from that in those not exposed to these conditions (Table 5). History of smoking was reported by 91 (13\%) athletes. Of these, 44 were current smokers (eight athletes 


\begin{tabular}{|c|c|c|c|c|}
\hline & $\begin{array}{l}\text { Among all subjects }(\%) \\
(n=698)\end{array}$ & $\begin{array}{l}\text { Subjects with asthma (\%) } \\
\qquad(n=107)\end{array}$ & $\begin{array}{l}\text { Subjects without asthma (\%) } \\
\qquad(\mathrm{n}=591)\end{array}$ & $\mathbf{P}$ \\
\hline \multicolumn{5}{|l|}{ Allergic conditions } \\
\hline Confirmed allergies & $143(20.5)$ & $56(52.3)$ & $87(14.7)$ & 0.0001 \\
\hline Hay fever & $145(20.8)$ & $38(35.5)$ & $107(18.1)$ & 0.0001 \\
\hline \multicolumn{5}{|c|}{ Respiratory conditions } \\
\hline Cold/influenza* & $552(79.1)$ & $83(77.6)$ & $469(79.4)$ & NS \\
\hline Respiratory infection & $90(12.9)$ & $27(25.2)$ & $63(10.7)$ & 0.0001 \\
\hline \multicolumn{5}{|l|}{ Family history } \\
\hline Asthma & $122(17.5)$ & $21(19.6)$ & $101(17.1)$ & NS \\
\hline Allergies & $302(43.4)$ & $53(49.5)$ & $249(42.1)$ & NS \\
\hline COPD & $21(3.0)$ & $9(8.4)$ & $12(2.0)$ & 0.002 \\
\hline \multicolumn{5}{|l|}{ Environment } \\
\hline Exposure to cats & $204(29.2)$ & $27(25.2)$ & $177(30.0)$ & NS \\
\hline Exposure to dogs & $211(30.2)$ & $26(24.3)$ & $185(31.3)$ & NS \\
\hline Bedroom carpeting & $291(41.7)$ & $38(35.5)$ & $253(42.8)$ & NS \\
\hline History of smoking & $91(13.0)$ & $11(10.3)$ & $80(13.5)$ & NS \\
\hline Current smoker & $44(6.3)$ & $6(5.6)$ & $38(6.4)$ & NS \\
\hline Exsmoker & $47(6.7)$ & $5(4.7)$ & $42(7.1)$ & NS \\
\hline
\end{tabular}

${ }^{*}$ In the last 12 months. COPD Chronic obstructive pulmonary disease; NS Not significant

reported smoking five or more cigarettes/week and 36 reported smoking less than five cigarettes/week) and 47 were exsmokers (seven athletes estimated smoking five or more cigarettes/week and 40 estimated smoking fewer than five cigarettes/week). Past or present history of smoking was not associated with asthma.

\section{DISCUSSION}

In the present survey, we found a prevalence of self-reported or physician-diagnosed asthma (15.3\%) similar to what has been previously reported among athletes. This prevalence is identical to the one found by Weiler et al (8) in summer Olympic Games athletes $(15.3 \%)$, although their criterion for asthma consisted of a previous diagnosis of asthma or exercise-induced asthma. Later, using the same criterion, the same author found a prevalence of $21.9 \%$ in winter Olympic Games athletes (7). Similar figures were also found by Heir and Oseid (11) and Voy (12) who reported a prevalence of asthma and exercise-induced asthma in athletes of $14.0 \%$ and $11.2 \%$, respectively, when using questionnaires.

In a previous study (4), we compared the prevalence of AHR in the same four groups of athletes (categorized by type of air inhaled during training) and found it to be remarkably high in swimmers $(79 \%)$ and in athletes training in CA (52\%). With the present study, we were expecting to find a similar tendency, but no significant differences were observed for the prevalence of asthma among the four groups. Moreover, the lowest prevalence of asthma was observed among athletes of the HA group, which had presented the highest prevalence of AHR in our previous study. This suggests a dissociation between what is measured by objective means for airway responsiveness and reported/diagnosed asthma evaluated by a survey questionnaire, especially for certain groups of athletes. Many factors might be responsible for the dissociation between prevalence of AHR and asthma, particularly for athletes of the HA group (swimming, synchronized swimming and water polo). For these athletes, this could indicate an under-recognition of asthma, possibly due to under-reporting or under-perception of respiratory discomfort in these athletes. In this regard, we previously showed that swimmers had a significantly lower perception of exercise-induced breathlessness when compared with the three other groups (13). This could also indicate that there is an overexpression of AHR in athletes training in indoor pools, possibly due to the longterm airway exposure to chlorine derivatives, leading to increased airway sensitivity to methacholine without inducing symptomatic asthma. For athletes training in cold air, similar factors could be involved, especially with regard to a possible overexpression of AHR that could result from long-term exposure to the cold air environment during training.

Perhaps certain athletes - for instance, those of the HA and CA groups - develop a temporal adaptation to nociceptive stimuli, such as respiratory discomfort during high-intensity training. It is also possible that the type of environment in which athletes of the HA or CA group train on a regular basis induces airway inflammation, sufficient to produce AHR, possibly from airway remodelling, but insufficient to generate perceivable symptoms. A possible reason to explain the discrepancy between studies using bronchial challenges (either with exercise or methacholine) and surveys using questionnaires could be the possible long-term temporal adaptation to respiratory symptoms. We have previously reported this feature following allergen challenge-induced late responses (14). In this regard, we recently extensively reviewed the problem of the discrepancy between physiological and clinical features observed in athletes (15).

In the present study, asthma did not correlate with any of the subject characteristics illustrated in Table 2 (all P>0.05).

The strong correlation of atopy and asthma in athletes is similar to the observations of Helenius et al (3). In the present study, we cannot exclude the possibility that patients with respiratory symptoms were more likely to have had allergy tests. It 
is also possible that subjects may not have remembered the results of their allergy tests correctly. Nevertheless, the prevalence of atopy was not significantly different among the four groups. This trend is similar to what we observed in our previous study (4). The similar prevalence of atopy observed in the four groups of athletes may suggest that the allergen content in inhaled air is not a major factor influencing the development of sensitization to common allergens in these athletes or that other factors are involved.

A family history of asthma and allergies was not correlated with a personal history of asthma in these athletes. The lack of correlation between a family history of asthma and asthma in athletes indicates that, contrary to what has been demonstrated for the general population, this genetic determinant may not play a major role in the development of asthma in the athletic population. Helenius et al (3) evaluated the family history of asthma in first-degree relatives of athletes and found no association between this parameter and asthma in athletes. Nevertheless, while a family history of asthma has been identified as a risk factor for the development of asthma in the general population $(16,17)$, more extensive studies should further investigate this aspect among athletes. Although the relationship between family history of COPD and personal history of asthma was statistically significant in our athletes, the significance of this finding is unclear and may be related to factors such as childhood exposure to second-hand smoke or an increased awareness toward respiratory conditions among their family. Finally, asthma was not more frequently reported in athletes exposed to animals, with bedroom carpeting or with a history of smoking.

Regarding limitations of the present study, a possible bias may have been introduced by the use of voluntary subjective reports. It is possible that athletes already concerned about their respiratory condition were more likely to fill out the questionnaire. It has been reported that lower response rates are observed when surveys are anonymous (18). The fact that this survey was made on an anonymous basis could perhaps have negatively influenced the response rate; however, the use of written reminders could have enhanced the response rate, as it has been demonstrated that surveys using written reminders obtain higher

\section{REFERENCES}

1. Sue-Chu M, Larsson L, Bjermer L. Prevalence of asthma in young cross-country skiers in central Scandinavia: Differences between Norway and Sweden. Respir Med 1996;90:99-105.

2. Weiler JM, Metzger WJ, Donnelly AL, Crowley ET, Sharath MD. Prevalence of bronchial hyperresponsiveness in highly trained athletes. Chest 1986;90:23-8.

3. Helenius IJ, Tikkanen HO, Sarna S, Haahtela T. Asthma and increased bronchial responsiveness in elite athletes: Atopy and sport event as risk factors. J Allergy Clin Immunol 1998;101:646-52.

4. Langdeau JB, Turcotte H, Bowie DM, Jobin J, Desgagné P, Boulet LP. Airway hyperresponsiveness in elite athletes. Am J Respir Crit Care Med 2000;161:1479-84.

5. Leuppi JD, Kuhn M, Comminot C, Reinhart WH. High prevalence of bronchial hyperresponsiveness and asthma in ice hockey players. Eur Respir J 1998;12:13-6.

6. Nystad W, Harris J, Borgen JS. Asthma and wheezing among Norwegian elite athletes. Med Sci Sports Exerc 2000;32:266-70.

7. Weiler JM, Ryan EJ 3rd. Asthma in United States olympic athletes who participated in the 1998 olympic winter games. J Allergy Clin Immunol 2000;106:267-71.

8. Weiler JM, Layton T, Hunt M. Asthma in United States Olympic athletes who participated in the 1996 Summer Games. J Allergy Clin Immunol 1998;102:722-6.

9. Helenius IJ, Tikkanen HO, Haahtela T. Association between type of training and risk of asthma in elite athletes. Thorax 1997;52:157-60. responses rates (18). The validity of physician-diagnosed asthma, and especially, self-reported asthma, could be one of the areas of uncertainty. Nevertheless, this method is currently used and is considered a valuable means of acquiring data on possible manifestations of diseases such as asthma in large populations. Data on the nonresponders would have been useful; however, this information was not available. It could also have been worthwhile to include normal controls in the present study, but our main goal was to compare the prevalence of asthma among groups of athletes rather than between athletes and nonathletes.

\section{CONCLUSIONS}

We previously reported that there was a high prevalence of AHR in high-level athletes and that among groups of athletes classified according to the type of air predominantly inhaled during training, this prevalence differed significantly. This led to the examination of the frequency of asthma in such athletes, but more precisely, to compare the prevalence of asthma among the four groups of athletes that had been previously defined. The present study showed a prevalence of asthma consistent with what has been reported by other surveys in athletes. The major observation was that, contrary to the significant variability in prevalence that was previously found for AHR in the four groups of athletes, in the present study, no significant differences were observed among the groups. In addition, athletes with asthma reported having confirmed allergies, hay fever and respiratory infection more frequently than those without asthma. There was a certain homogeneity among the four groups of athletes, regardless of the type of air they regularly inhaled during training. Lastly, a family history of asthma (with the exception of COPD) and environmental factors such as animal, carpet and smoke exposure did not correlate with the diagnosis of asthma in these athletes.

ACKNOWLEDGEMENTS: The authors would like to thank Serge Simard for his statistical analysis of the data and Lori Henig Schubert for reviewing the manuscript. The authors would also like to thank the Secrétariat aux loisirs et aux sports (government of Quebec) for its financial support to this project. The authors are grateful to all subjects who participated in this study.

10. Variations in the prevalence of respiratory symptoms, self-reported asthma attacks, and use of asthma medication in the European Community Respiratory Health Survey (ECRHS). Eur Respir J 1996;9:687-95.

11. Heir T, Oseid S. Self-reported asthma and exercise-induced asthma symptoms in high-level competitive cross-country skiers. Scand J Med Sci Sports 1994;4:128-33.

12. Voy RO. The U.S. Olympic Committee experience with exerciseinduced bronchospasm, 1984. Med Sci Sports Exerc 1986;18:328-30.

13. Turcotte H, Langdeau J-B, Bowie DM, Boulet L-P. Efficacy of questionnaires on respiratory symptoms to detect airway responsiveness in elite athletes and sedentary subjects. Am J Respir Crit Care Med 1999; 159:A757. (Abst)

14. Turcotte H, Boulet LP. Perception of breathlessness during early and late asthmatic responses. Am Rev Respir Dis 1993;148:514-8.

15. Langdeau JB, Boulet LP. Is asthma over- or under-diagnosed in athletes? Respir Med 2003;97:109-14.

16. Genes for asthma? An analysis of the European Community Respiratory Health Survey. Am J Respir Crit Care Med 1997;156:1773-80.

17. Lundback B. Epidemiology of rhinitis and asthma. Clin Exp Allergy 1998;28(Suppl 2):3-10.

18. Asch DA, Jedrziewshi MK, Christakis NA. Response rates to mail surveys published in medical journals. J Clin Epidemiol 1997;50:1129-36. 


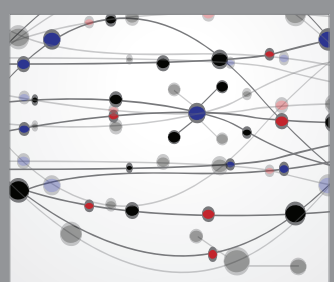

The Scientific World Journal
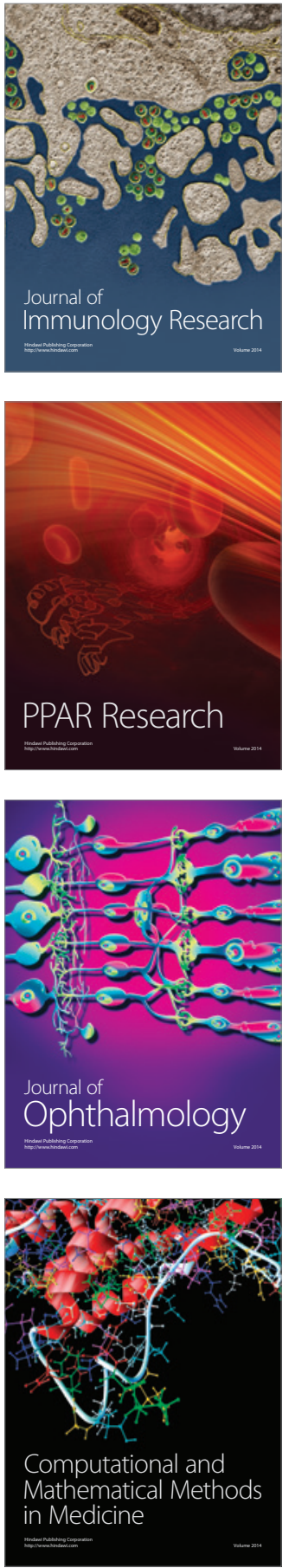

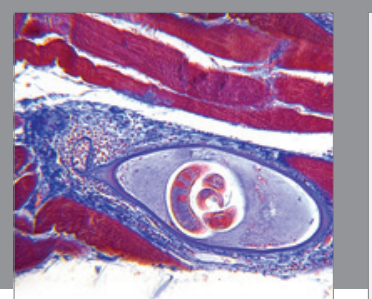

Gastroenterology Research and Practice

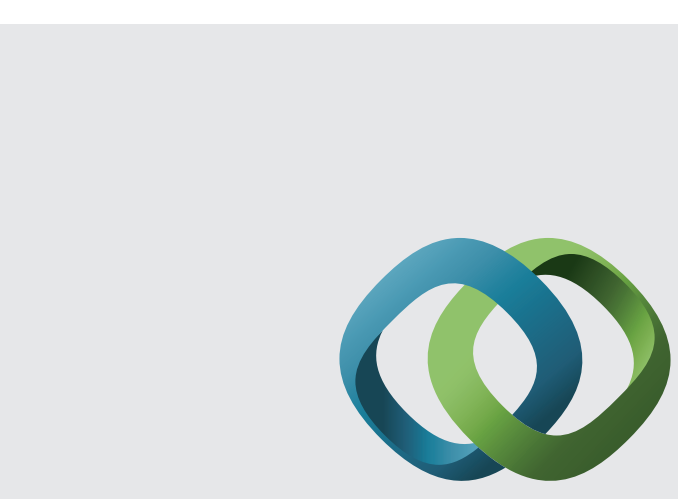

\section{Hindawi}

Submit your manuscripts at

http://www.hindawi.com
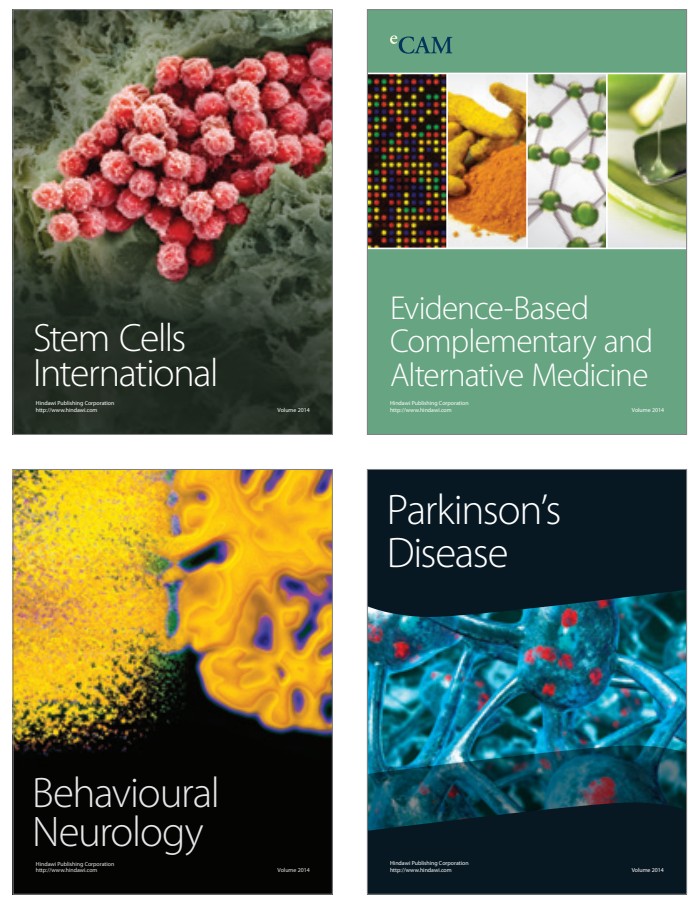
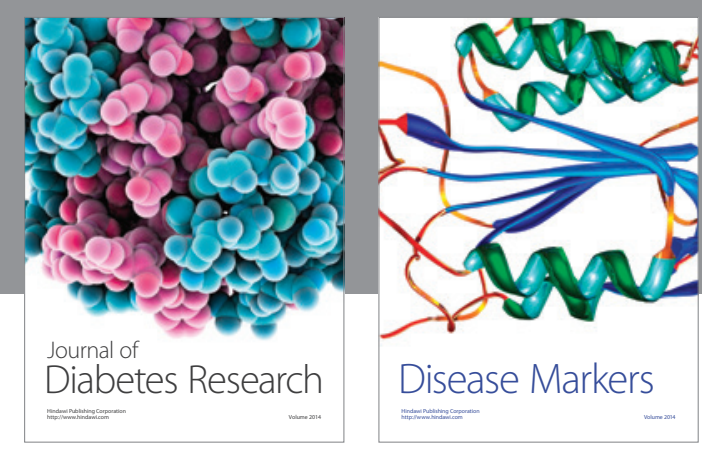

Disease Markers
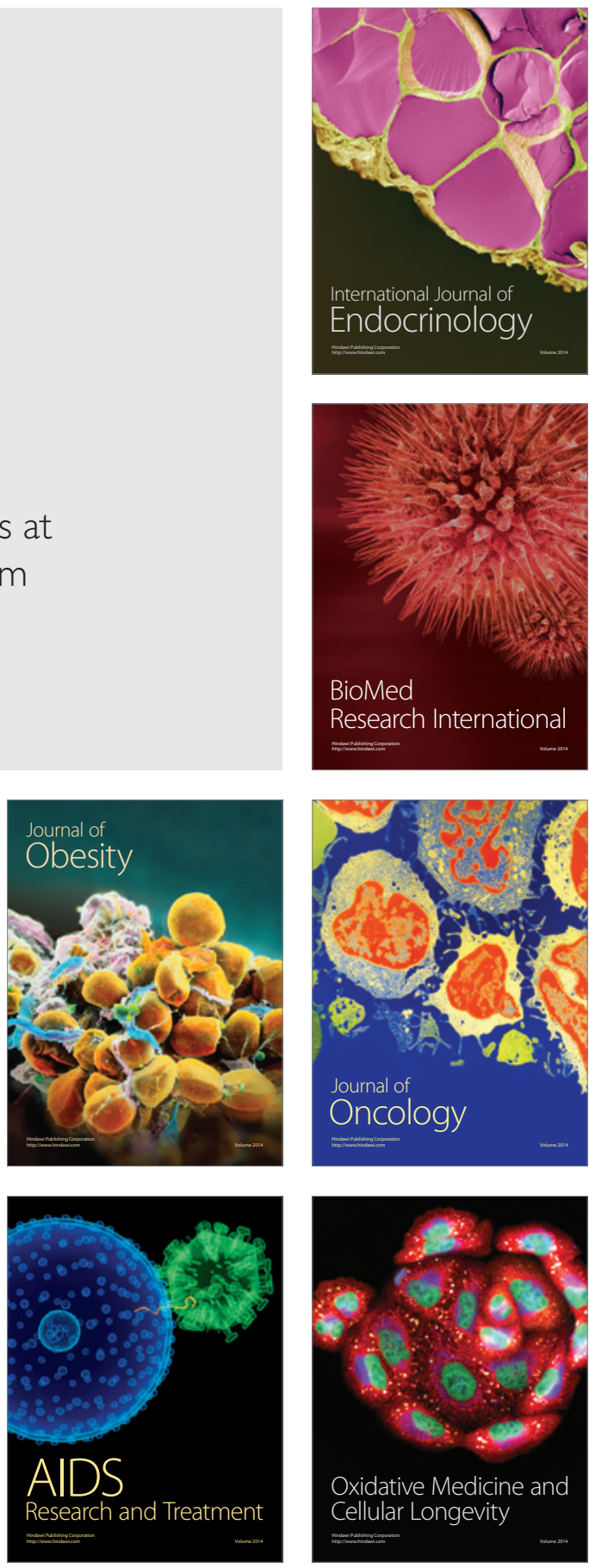